\title{
Selective Antecedents of Competitive State Anxiety Dimensions During High Stakes in Elite Competition
}

\author{
Hagan Junior John Elvis ${ }^{1,2, ~ *, ~ P o l l m a n n ~ D i e t m a r ~}{ }^{1}$, Schack Thomas ${ }^{1,2}$ \\ 1"Neurocognition and Action - Biomechanics" - Research Group, Faculty of Psychology and Sport Sciences, Bielefeld University, Bielefeld, \\ Germany \\ ${ }^{2}$ Center of Excellence "Cognitive Interaction Technology" CITEC, Bielefeld University, Bielefeld, Germany
}

Email address:

elvis.hagan@ucc.edu.gh(H. J. J. Elvis)

${ }^{*}$ Corresponding author

\section{To cite this article:}

Hagan Junior John Elvis, Pollmann Dietmar, Schack Thomas. Selective Antecedents of Competitive State Anxiety Dimensions During High Stakes in Elite Competition. American Journal of Sports Science. Vol. 6, No. 3, 2018, pp. 88-97. doi: 10.11648/j.ajss.20180603.14

Received: April 24, 2018; Accepted: May 10, 2018; Published: May 28, 2018

\begin{abstract}
This present study investigated the influence of competitive state anxiety antecedents on the intensity, direction, and frequency dimensions of elite athletes during high stakes in table tennis competition. Thirty-three $(\mathrm{N}=33)$ purposively sampled elite table tennis players from Ghana completed the modified version of the Competitive State Anxiety Inventory-2, incorporating the direction and frequency of intrusion subscales during breaks within competitive matches. Hierarchical multiple regression analyses on intensity dimension revealed that cognitive anxiety was significantly predicted by only the age factor while no predictors emerged for somatic anxiety. Self-confidence was significantly predicted by only competitive experience. For directional dimension, gender and age emerged as significant predictors of cognitive anxiety. However, none of the factors were found to significantly predict somatic anxiety and self-confidence. Regarding frequency dimension, cognitive anxiety was significantly related to competitive experience and age whereas no predictors emerged for somatic anxiety. Competitive experience factor was also significantly associated with self-confidence. Findings underscore the need to measure these anxiety dimensions concurrently because they are triggered by different antecedents. Psychological skills interventions should be idiosyncratic based, targeting more self-confidence management strategies in alleviating the effect of cognitive anxiety during competitive matches when demands are very high.
\end{abstract}

Keywords: Self-Confidence, Intensity, Direction, Frequency, State Anxiety

\section{Introduction}

Competitive anxiety forms an integral aspect of sport for many athletes, with a commonly held belief that attaining and sustaining an appropriate emotional state prior to and during performance is central to success or decline in performance [1-3]. Hence, the maintenance of optimal performance state is not only crucial prior to competition but also significant during competitive fixtures as a key determinant for performance success $[4,5]$.

Much anxiety research to date has adopted the multidimensional theory as a framework to examine the intensity [6], directional interpretation [7], and frequency [8] of cognitive, somatic, and self-confidence symptoms [2, 911]. These multidimensional anxiety studies suggest that different dimensions (intensity, direction, and frequency) of competitive anxiety tend to be influenced by gender, type of sport, skill level, and competitive experience [6, 10-14]. Other situational antecedents as varied as perceived threat $[15,16]$, perceived importance [17], perceived success and failure [18] have been earlier identified.

Therefore, the identification of competitive anxiety antecedents in sport has become a critical research area for both theoretical and applied reasons [6, 19]. Reasonably, gaining further insights into performance variables that may elicit anxiety symptoms of athletes will not only aid conceptual understanding, but may also enhance in the development of effective design and implementation of appropriate psychological interventions [20-22]. In spite of this growing body of literature about the dimensions of multidimensional anxiety, there still remains a dearth of 
empirical evidence regarding their comprehensive examination associated with related antecedents that may elicit these emotional experiences from elite athletes in one research design, especially during competitive events $[10,11$, 23].

To date, most competitive anxiety studies have reported gender to differentiate the expression of anxiety with a commonly held assumption that female athletes feel more cognitively and somatically anxious than their male counterparts, with a further debilitative interpretation of these anxiety symptoms, and decline in self-confidence [24-26]. However, these findings have been challenged in other studies [27, 28]. For instance, Hagan, Pollmann, and Schack [27] found that elite females were less cognitively anxious, interpreted somatic symptoms as more facilitative and were more stable days leading to a competitive fixture compared to their male group. Cultural influences were cited to have potentially accounted for these findings.

Research so far has identified elite athletes to report more facilitative interpretations of anxiety symptoms with greater self-confidence than their sub-elite group [14, 29-31]. In spite of the fact that skill level research has been consistent, a related variable that has received little investigation in anxiety literature is the amount of experience athletes possess in their respective sport [14]. Even though skill level is viewed as an objective individual ability at a certain sporting level (i.e., National or International), the concept of sport experience is additionally associated with the familiarity or unfamiliarity of the environment to the individual [32]. The existing skill classification system suggests that it is likely athletes may be classified as highly skilled yet be very low in experience due to a sudden rise in performance in their particular sport or event. Only few studies have inferred that high standard athletes will usually be those of greater experience, with findings suggesting that more experienced and highly skilled performers reporting lower intensity levels of symptoms associated with anxiety, which were interpreted as facilitative as well as displaying high self-confidence toward an upcoming task [14].

Additionally, chronological age which is closely associated with the amount of competitive experience athletes may possess could as well impact on competitive anxiety. It is possible that older or more experienced athletes might be less affected by associated anxiety related symptoms than the younger or less experienced performers who might be skilled or otherwise. For example, Hammermeister and Burton [33] found that older endurance athletes reported significantly less cognitive anxiety than their younger counterparts due to the adoption of less ego-threatening goals for participation. Similarly, other studies have reported lower state anxiety symptoms in older and more experienced athletes [34, 35]. These collective findings with athletes of varied experience underscore the need for furthering our knowledge on specificities that may predict these emotional experiences in an ecologically valid context, especially in other sport with different task characteristics and complexity during competitive fixtures.
One sport that has rarely been study and in motor behavior terms offers different task characteristics and complexity is table tennis (T. T). Table tennis, like other fast paced and reactive games, has a very short response window often dictated by the speed, direction and rotation of the ball which often forces performers to use advanced cues to decide what response is required and what movements ought to be calibrated. Therefore, the personal exposure in TT places enormous emotional and cognitive load on performers due to its task complexity and situational demands. For instance, each distraction and emotional instability of athletes' immediate competing environment may result in a series of technical faults or errors that will subsequently impact on match outcomes [36, 37].

To date, little is known about the possible antecedents of the intensity, directional, and frequency components of competitive anxiety (multidimensionality) collectively in one research design. Previous studies have examined these dimensions separately, suggesting that these assessments may not present or reflect a comprehensive picture of athletes' anxiety symptoms since their combined influence may elicit different antecedents compared to the antecedents and effects of their separate measurement. From applied perspective, comprehensive measurement will prompt the adoption of appropriate design of psychological interventions that may commensurate the magnitude of anxiety impact. Thus, the present study investigated selected antecedents of intensity, direction, and frequency of multidimensional anxiety and considered the relative impact of each predictor variable (personal: age and gender; situational: competitive experience) of the aforementioned anxiety dimensions during high stakes in competitive matches that previous research has ignored. Based on previous research [12, 14, 27, 33, 34, 35], it was hypothesized that gender, age and competitive experience would significantly be associated with cognitive and somatic anxiety as well as self-confidence across all the anxiety dimensions (intensity, direction and frequency).

\section{Materials and Methods}

\subsection{Participants}

Data collection for the study was obtained from a purposively sampled participants $(\mathrm{N}=33)$ comprising Ghanaian male and female competitive athletes of elite status from the national league organized by the Ghana Table Tennis Association. The ages of participants range from 21 to 32 years $(M=25.67, S D=3.50)$. Players' inclusion criteria included a minimum of 5 years competitive playing experience at either the national or international level or both, and train four times a week on the average. Criteria for elite status was based upon previous classifications that stated participants had to be currently competing or have competed in both national and international competition [14, 38, 39]. Preceding the data collection, all participants provided informed written consent to the researcher. Confidentiality and anonymity of all study participants were well-maintained 
at all stages of the investigation, with assurance that data collected would remain confidential and were only for academic purposes. Participation was completely voluntary by which study participants could stop answering the survey at any point they felt to do so. At the time of data collection, all participants were competing in the Ghana national league. This research procedure was approved by the Institutional Review Board (IRB [Ethics Committee]) at Bielefeld University and adhered to the ethical standards of the latest revision of the Declaration of Helsinki.

\subsection{Instrumentation}

The modified version of the CSAI-2 [6] was used to examine the intensity, direction, and frequency of performance related cognitive anxiety, somatic anxiety, and self-confidence with nine items on each subscale. Participants rated the intensity of each item on a scale anchored by 1 ("not at all") and 4 ("very much so"), with overall subscale intensity scores ranging from 9 to 36 . Satisfactory internal consistency for the intensity subscale has been reported previously with Cronbach alpha coefficients ranging from 0.79 to 0.90 [6]. Jones and Swain's [40] direction scale was added to each item, of which each participant rated the degree to which the experienced intensity of each symptom was either facilitative or debilitative towards their performance using a bipolar scale ranging from -3 ("very debilitative") to +3 ("very facilitative"). Overall subscale direction scores range from 27 to +27 , where a negative score denotes a debilitative state and a positive score as facilitative experience. Reported internal reliability coefficients for the direction subscale range from 0.72 to $0.90[15,41-43]$. Additionally, the frequency of intrusions scale, developed by Swain and Jones [42], was also included in the modified CSAI-2. This scale assesses the degree of symptom related thoughts or experiences on a scale ranging from 1 ('not at all') to 7 ('all the time') for each item on the inventory. Reported internal reliability coefficient values for this scale range from.70 to.93 [11]. In the current study, Cronbach reliability scores reported range from.71 to.79 for the intensity dimension,.74 to. 80 for the direction dimension and.72 to.78 for the frequency dimension, values that are reckoned to be acceptable.

\subsection{Procedure}

A brief introductory session was held for participants to explain the format for the completion of the modified CSAI2 instrument. Participants were required to note their intensity, interpretation and frequency of cognitive, somatic symptoms and self-confidence experienced at the moment ("right now") during the survey periods of their competitive engagements.

The 33 participants were subsequently monitored under high stressful conditions during competitive fixtures at a national championship dubbed "Top Ten" organized purposely to select players for an impending international tournament. Using the experience sampling method, momentary assessments of selected anxiety variables (cognitive, somatic, and self-confidence) were taken during intervals or breaks between matches at the three-day championship. To minimize possible intrusiveness, the assessments were staggered over a three-day period. Specifically, Stressful status was determined by the potential imbalance between demand and response capability, where failure to meet the demand may have important consequences. A competition for final team places could be one potential situational stressor that is likely to induce some emotional experiences of athletes and was considered "high stressful". By this, competitive stakes are assumed to be very high because previous research has shown that emotions are probably more intense when highly valued goals are at stake $[44,45]$. Competitive environment such as this usually has a higher demand and importance. The completion of the instrument was triggered by a random signal during breaks between matches during the competition.

\subsection{Data Analyses}

Data analyses were divided into different stages. First, data prescreening procedures were conducted to examine the accuracy of the data and statistical assumptions. Second, descriptive statistics (Means and Standard deviations) and Pearson correlations for all the subscales on the modified CSAI-2 were computed. Third, in order to identify which of the three antecedents significantly predicted each subcomponent of the multidimensional anxiety on the separate dimensions measured by the modified CSAI-2 inventory, hierarchical regression analyses were performed using data from momentary self-reported assessments. In the regression model, two personal factors (gender, age) were assigned first entry and competitive experience (situational) factor was assigned second entry. This process was repeated for all multidimensional competitive anxiety (CA, SA, SC) and on each response dimension (intensity, direction, frequency). The regression aimed at testing the predictive ability of gender and age (as it is currently measured) in relation to multidimensional competitive anxiety (cognitive, somatic, self-confidence) on each dimension (intensity, direction, frequency) and evaluated whether competitive experience significantly added to the explanation of the personal factors in the model over and above all the anxiety related constructs.

\section{Results}

\subsection{Preliminary Analysis}

Prior to conducting the hierarchical multiple regression analyses, the relevant assumptions of this statistical analysis were tested. A sample size of 33 was deemed adequate given the three independent variables that were included in the analyses [46]. The assumption of singularity was also met as the independent variables (i.e., gender, age, competitive experience) were not a combination of other independent 
variables. An examination of correlations (see Table 1) revealed that no independent variables were highly correlated. The collinearity statistics (i.e., Tolerance and VIF) were all within acceptable limits as well as the assumption of multicollinearity was deemed to have been met [46, 47]. No univariate outliers were identified in the initial data screening. An examination of the Mahalanobis distance scores indicated no multivariate outliers. Residual and scatter plots revealed that the assumptions of normality, linearity and homoscedasticity were all satisfied [46-47].

\subsection{Main Analyses}

Pearson Correlations amongst the predictor variables (gender, age, competitive experience) were examined together with the dependent variables (competitive anxiety on intensity, direction, and frequency dimensions) which are presented in Table 1. The significant correlations were weak to moderate, ranging between $\mathrm{r}=.36, \mathrm{p}<.05$ and $\mathrm{r}=.58$, $\mathrm{p}$ $<.01$. This indicates that multicollinearity was unlikely to be a problem $[46,47]$. However, SAI and SAF $(r=.69, \mathrm{p}<.05)$ as well as SCI and SCF $(\mathrm{r}=.70, \mathrm{p}<.05)$ correlation values were high although satisfactory for analyses. All predictor variables were suitably correlated with the dependent variables for the examination through Hierarchical multiple regression. The correlations between the predictor variables and the dependent variables were also weak to moderate, ranging from $\mathrm{r}=-.05, \mathrm{p}<.05$ to $\mathrm{r}=.49, \mathrm{p}<.001$.

Table 1. Correlations, Means and Standard Deviations for CSAI-2 Subscale Scores.

\begin{tabular}{|c|c|c|c|c|c|c|c|c|c|c|c|c|}
\hline Variable & G & $\mathbf{A}$ & $\mathbf{C E}$ & CAI & SAI & SCI & CAD & SAD & SCD & CAF & SAF & SCF \\
\hline \multicolumn{13}{|l|}{ Gender $(\mathrm{G})$} \\
\hline Age (A) & -28 & & & & & & & & & & & \\
\hline Competitive & & & & & & & & & & & & \\
\hline Experience (CE) & .15 & -.29 & & & & & & & & & & \\
\hline $\begin{array}{l}\text { Cognitive anxiety } \\
\text { intensity (CAI) }\end{array}$ & .31 & $-.50 * *$ & .18 & & & & & & & & & \\
\hline $\begin{array}{l}\text { Somatic anxiety } \\
\text { intensity (SAI) }\end{array}$ & .06 & $-.37 *$ & .22 & $.65^{* *}$ & & & & & & & & \\
\hline Self-confidence & 07 & -18 & & 01 & 12 & & & & & & & \\
\hline $\begin{array}{l}\text { Cognitive anxiety } \\
\text { direction (CAD) }\end{array}$ & $-.52 * *$ & $.47 * *$ & -.20 & -.26 & -.10 & .03 & & & & & & \\
\hline $\begin{array}{l}\text { Somatic anxiety } \\
\text { direction (SAD) } \\
\text { Self-confidence }\end{array}$ & -.23 & .15 & .04 & .01 & -.18 & -.07 & $.52 * *$ & & & & & \\
\hline $\begin{array}{l}\text { Cognitive anxiety } \\
\text { frequency (CAF) } \\
\text { Somatic anxiety }\end{array}$ & .14 & $-.50 * *$ & $.49 * *$ & $.58 * *$ & $.55^{* *}$ & $.40^{*}$ & .06 & .30 & .16 & & & \\
\hline $\begin{array}{l}\text { Frequency (SAF) } \\
\text { Self-confidence }\end{array}$ & -.02 & -.30 & .14 & $.56^{* *}$ & $.69 * *$ & .29 & -.07 & -.10 & .15 & $.58 * *$ & & \\
\hline Frequency (SCF) & .04 & .03 & $.36^{*}$ & -.21 & -.12 & $.70 * *$ & -.02 & -.16 & $.41 *$ & .18 & .09 & \\
\hline Means & - & 25.67 & 8.42 & 26.48 & 23.94 & 33.88 & 5.00 & -1.64 & 16.03 & 33.27 & 30.03 & 52.18 \\
\hline Standard deviation & - & 3.50 & 2.17 & 5.39 & 5.11 & 4.95 & 5.99 & 5.36 & 4.05 & 7.58 & 9.31 & 9.75 \\
\hline
\end{tabular}

** Correlation is significant at the 0.01 (2 tailed)

* Correlation is significant at the 0.05 ( 2 tailed)

\subsection{Predictions on Competitive State Anxiety Dimensions}

Hierarchical multiple regression analyses were employed to establish the extent to which, if any, of the three factors significantly predicted intensity, direction and frequency of Competitive State Anxiety Inventory-2 subcomponents in elite table tennis athletes.

\subsubsection{Anxiety Intensity Dimension}

The first hierarchical multiple regression showed that at step one only age contributed significantly to the regression model, $\mathrm{F}(2,30)=5.82 ; \mathrm{p}<.05$ and explained $28 \%$ of variance in cognitive anxiety intensity. Introducing competitive experience to the model did not account for any additional contribution to the model (see Table 2). The second hierarchical regression revealed that neither the first model (gender, age) nor the second model (competitive experience) predicted scores of somatic anxiety intensity to a significant degree.

No significant predictors of self-confidence intensity emerged for the first model of the third hierarchical regression analysis. However, the inclusion of competitive experience accounted significantly to the second model, F (3, $29)=2.70 ; p<.05$, explaining an additional $19 \%$ of variance in self-confidence intensity.

\subsubsection{Anxiety Direction Dimension}

For the fourth hierarchical regression, factors (gender and age) emerged as significant predictors of the first regression model, $\mathrm{F}(2,30)=9.19 ; \mathrm{p}<.001$ and explained $38 \%$ variance in cognitive anxiety direction (see Table 2 ). The introduction of competitive experience to the model 2 yielded no additional contribution over and above the model in predicting scores of cognitive anxiety direction in the elite athletes. 
The fifth and sixth hierarchical regression analyses showed no significant predictions of the first model (gender, age) and the second model (competitive experience) of somatic anxiety and self-confidence direction respectively (see Table 2).

\subsubsection{Anxiety Frequency Dimension}

Table 2 shows $25 \%$ of the total variance in cognitive anxiety frequency was explained by only the age factor in the first step of the regression model, F $(2,30)=5.02 ; \mathrm{p}<.05$ for the seventh hierarchical regression analysis. After entry of competitive experience at Step 2, the variance explained by the model as a whole was $13 \%, \mathrm{~F}(3,29)=5.99 ; \mathrm{p}<.05$, explaining an additional $13 \%$ of variance in cognitive anxiety frequency (see Table 2). The eight analyses revealed that neither the first model (gender, age) nor the second model (competitive experience) significantly predicted scores for somatic anxiety frequency.

No significant predictors of self-confidence frequency emerged for the first model of the last hierarchical regression analysis. However, the entry of competitive experience accounted significantly to the model $2, \mathrm{~F}(3,29)=1.66$; p $<.05$, explaining an additional $14 \%$ of variance in selfconfidence frequency scores.

Table 2. Hierarchical Regression Analyses of Competitive Anxiety and Self-confidence.

\begin{tabular}{|c|c|c|c|c|c|c|c|c|}
\hline CSAI-2 Subcomponent & Predictor & $\mathbf{R}$ & $\mathbf{R}^{2}$ & $\mathbf{R}^{2}$ Change & B & SE & $\beta$ & $\mathbf{t}$ \\
\hline \multirow{4}{*}{ Intensity } & Regression 1 & & & & & & & \\
\hline & Step 1 & .53 & .28 & $.28 *$ & & & & \\
\hline & Gender & & & & 1.10 & 1.72 & .19 & 1.16 \\
\hline & Age & & & & -.68 & .25 & $-.44 *$ & -2.75 \\
\hline \multirow[t]{5}{*}{ CAI } & Step 2 & .53 & .28 & .00 & & & & \\
\hline & $\begin{array}{l}\text { Competitive } \\
\text { experience } \\
\text { Regression } 2\end{array}$ & & & & 0.52 & 0.41 & .02 & .13 \\
\hline & Step 1 & .37 & .14 & .14 & & & & \\
\hline & Gender & & & & -.47 & 1.79 & -.05 & -.27 \\
\hline & Age & & & & -.56 & .26 & -.38 & -2.17 \\
\hline \multirow[t]{5}{*}{ SAI } & Step 2 & .39 & .15 & .02 & & & & \\
\hline & $\begin{array}{l}\text { Competitive } \\
\text { experience } \\
\text { Regression } 3\end{array}$ & & & & .30 & .42 & .13 & .72 \\
\hline & Step 1 & .18 & .03 & .03 & & & & \\
\hline & Gender & & & & .16 & 1.84 & .02 & .09 \\
\hline & Age & & & & -.24 & .27 & -.17 & -.91 \\
\hline \multirow[t]{2}{*}{$\mathrm{SCI}$} & Step 2 & .47 & .22 & $.19 *$ & & & & \\
\hline & $\begin{array}{l}\text { Competitive } \\
\text { experience } \\
\text { Regression } 4\end{array}$ & & & & 1.04 & .39 & $.45^{*}$ & 2.64 \\
\hline \multirow{3}{*}{ Direction } & Step 1 & .62 & .38 & $.38^{*}$ & & & & \\
\hline & Gender & & & & -4.66 & 1.66 & $-.42 *$ & -2.81 \\
\hline & Age & & & & .55 & .24 & $.35^{*}$ & -.27 \\
\hline \multirow[t]{3}{*}{ CAD } & Step 2 & .61 & .38 & .00 & & & & \\
\hline & $\begin{array}{l}\text { Competitive } \\
\text { Experience } \\
\text { Regression } 5\end{array}$ & & & & -.11 & .40 & -.04 & -.27 \\
\hline & Step 1 & .25 & .06 & .06 & & & & \\
\hline \multirow[t]{4}{*}{ SAD } & Gender & & & & -2.09 & 1.96 & -.20 & -1.07 \\
\hline & Age & & & & .15 & .28 & .10 & .54 \\
\hline & Step 2 & .27 & .07 & .01 & & & & \\
\hline & $\begin{array}{l}\text { Competitive } \\
\text { Experience }\end{array}$ & & & & .28 & 46 & .11 & .59 \\
\hline
\end{tabular}

Table 2. Continued.

\begin{tabular}{|c|c|c|c|c|c|c|c|c|}
\hline CSAI-2 Subcomponent & Predictor & $\mathbf{R}$ & $\mathbf{R}^{2}$ & $\mathbf{R}^{2}$ Change & B & SE & $\beta$ & $\mathbf{t}$ \\
\hline \multirow{5}{*}{ SCD } & Regression6 & & & & \multirow{5}{*}{$\begin{array}{l}-1.21 \\
.29\end{array}$} & \multirow{4}{*}{$\begin{array}{l}1.44 \\
.21\end{array}$} & \multirow{4}{*}{$\begin{array}{l}-.15 \\
.25\end{array}$} & \multirow{4}{*}{$\begin{array}{l}-.84 \\
1.39\end{array}$} \\
\hline & Step 1 & .32 & .11 & .11 & & & & \\
\hline & Gender & & & & & & & \\
\hline & Age & & & & & & & \\
\hline & Step 2 & .41 & .18 & .06 & & & & \multirow[b]{2}{*}{1.46} \\
\hline \multirow{6}{*}{ Frequency } & $\begin{array}{l}\text { Competitive } \\
\text { Experience }\end{array}$ & & & & \multirow[t]{2}{*}{.48} & .33 & .26 & \\
\hline & Regression 7 & & & & & & & \\
\hline & Step 1 & .50 & .25 & $.25^{*}$ & & & & \\
\hline & Gender & & & & -.04 & 2.47 & -.00 & -.02 \\
\hline & Age & & & & -1.09 & .36 & $-.50 *$ & -3.05 \\
\hline & Step 2 & .62 & -.38 & $-.38 *$ & & & & \\
\hline
\end{tabular}




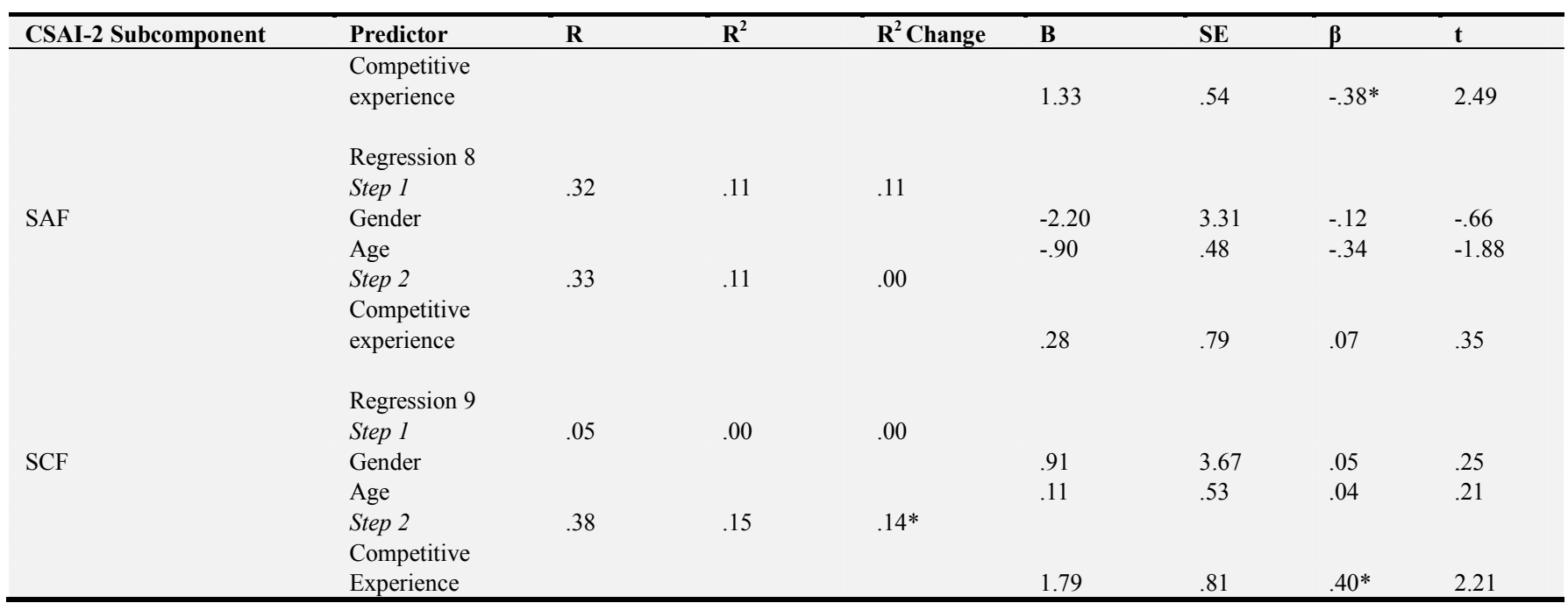

\section{Discussion}

The strength of this study was the use of elite table tennis players competing in a natural field setting, which has been suggested to be the most attractive environment for the study of complex emotional variable like competitive anxiety [48, 49]. Given that in high achievement sport, the individualoriented approach, together with the content of emotional experiences are often critical toward success or failure as well as personal satisfaction (i.e., feeling good or bad; [50]), it is surprising about the paucity of empirical evidence accounting for the predictive ability of personal and situational related factors on multidimensional competitive anxiety dimensions, especially during high stakes of elite competitive matches. The central aim of this study was to examine the relative influence of age, gender, and competitive experience on associated anxiety components of elite table tennis players from Ghana through the use of ecological momentary assessment within breaks in competitive matches. Preliminary correlational findings suggest that elite athletes with high scores of self-confidence tend to report low levels and frequency of cognitive, somatic anxiety, with facilitative interpretation of the same symptoms and vice versa.

Hypotheses formulated in this current study were partially supported. The main hierarchical regression results on intensity revealed that only age significantly predicted cognitive anxiety with $28 \%$ of variance accounting for its possible effect, a finding that corroborates other studies that found support for only cognitive anxiety [33-35]. Potentially, this means that older athletes are likely to be less cognitively anxious than their younger counterparts, presumably as a result of adopting less ego-threatening goals during competition and vice versa. The results further show that none of the three factors significantly predicted somatic anxiety. We argue that performance related expectancies (goals and values) during competition are more strongly related to cognitive anxiety through appraisals (primary and/ or secondary) than somatic anxiety $[44,51]$. Hence, the failure of these factors to predict somatic anxiety is perhaps not surprising since none of these aforementioned variables are reflexive (situational) stimuli or condition responses [6, 21]. This means rationalizing thoughts through self-reflection and awareness of the demands of a situation is more cognitive based and person oriented. Intensity of selfconfidence scores of the elite table tennis players were significantly predicted by competitive experience, accounting for $19 \%$ of variance, a finding that has been echoed in similar studies $[13,14]$. Reasonably, a higher standard athlete with much competitive experience is expected evoked high selfefficacy beliefs that may moderate the effects of cognitive anxiety and physiological arousal on performance. Specifically, self-confidence is purported to increase the probability that cognitively anxious performers can still tolerate higher levels of arousal before experiencing a decrement in performance [52]. Suggesting that elite athletes with competitive experience who display high intensities of anxiety (e.g., cognitive) and self-confidence simultaneously may still perform successfully whereas performers who experience high anxiety intensities without the accompanying feelings of self-confidence may suffer performance decline [10].

For the directional dimension, gender and age emerged as significant predictors of cognitive anxiety which explained on a whole, $38 \%$ of variance on reported scores. Only few studies have shown the association of anxiety interpretation of athletes who demonstrate high levels of competitiveness [40] and perform at elite level [7, 53] across gender and age. Due to limited scholarly information available, we draw on the initial work of Carver and Scheier [54, 55]. Their model indicates a combination of individual difference variables (e.g., gender, age) to control a stressor may underpin how athletes will interpret anxiety associated symptoms (debilitative or facilitative) toward performance. Therefore, the gender and age of athletes may influence cognitive appraisal processes that may determine the degree of influence they might exert over and above the environment and the self [30]. The implication is that performers across gender and of different ages who have more control over 
themselves and the situation are likely to cope with their anxiety and achieve their goals (i.e., cope). They are predicted to interpret symptoms as facilitative toward performance. Conversely, performers who are not in control of themselves and of different age band are likely not to cope with the situation at hand as well as show negative tendencies regarding goal attainment, will interpret such symptoms as debilitative [56]. Future researchers should consider how cognitive, emotional, and biological maturation may impact on stressful situations in competitive sport across gender and different age categories. This will aid in the development of talent identification and expertise profiles in sport [57].

The significant predictors emerging for cognitive anxiety frequency are age, which accounted for $25 \%$ of variance on the reported scores and competitive experience, explaining an additional $38 \%$ variance on cognitive anxiety frequency scores. Indeed, if valence of anxiety can change over time, then these predictions should be of interest due to their association with a metric component (time, frequency) of state anxiety reactions across different circumstances. Owing to the relative infant status of the frequency based studies, we speculate the competitive experience should have an overriding influence on frequency of cognitive intrusions during high stakes in elite sport, especially in reactive sport like table tennis than age, although related. Logically, it is unlikely that absolute age can be equated with the amount of experience an athlete possesses as suggested by its conceptualization:

"The current product of a process whereby knowledge is acquired and adapted so that action, reflection, and learning takes place. This occurs as a result of exposure to a variety of personally significant incidents, both positive and negative in nature, so that the aim (goal) of the action is achieved. This can take place in different environments, be it training, competition, or lifestyle" [58], p 32.

Therefore, it is possible that more experienced athletes might be less affected by associated anxiety related symptoms than the less experienced performers who might be skilled but younger in terms of age. Therefore, elite athletes with much considerable competitive experience in their sport, yet young, are likely to report less frequency of intrusions of worries or show apprehension in high demanding situations during competitive fixtures and vice versa. This assertion is supported by the negative correlation $(\mathrm{r}=-.29)$ and beta $(\beta=-.38)$ values noted between competitive experience and age as well as significantly predicting cognitive anxiety frequency (see Tables 1,2). These findings suggest that unfamiliarity and the risk involved in competing at a higher level may exert a significant effect on athletes' state anxiety during competition [32].

Competitive experience again significantly predicted and explained $14 \%$ variance of self-confidence frequency, depicting a common antecedent for cognitive anxiety frequency. These illustrations show that self-confidence could act as a resilient or buffering factor towards moderating the effect of both intensity and frequency of cognitive anxiety. These findings are not surprising because competitive experience of elite athletes, especially in reactive sport like table tennis where tasks are discontinuous and of short duration, require cognitive flexibility to calibrate appropriate responses to a wide array of unpredicted, unanticipated and ever-changing environmental stimuli [59, 60]. The lack of competitive experience may as well elicit lower level and frequency display of self-confidence. This situation may trigger external distractions from the environment and prevent elite players from discriminating between task relevant from irrelevant information [59]. These distortions are likely to affect the neuromuscular control mechanisms causing technical errors and other stroke related problems such as instability of chosen techniques, sudden decline of skill execution as well as habitual performance errors that may produce inconsistent results under stressful situations [50].

We argue that when athletes are faced with competition related adversities, those with considerable competitive experience who frequently display self-confidence, are likely to withstand the rigorous of competition demands with renewed effort and attention toward the goal of competition. Comparatively, those athletes who lack self-confidence and/ or display less of it are unlikely to cope and persist when experiencing anxiety symptoms and other task related difficulties, often leading to a focus on self-doubt and perceptions of inadequacy (low self-confidence; [61]).

\section{Practical Implications}

The contextual dimension associated with this study suggests that displayed emotional experiences were possibly triggered by intra-group and situational appraisal that determined which responses were evoked during high stakes in table tennis matches. Context may also include culturally coded and determined beliefs of athletes that may also elicit or suppress specific emotional coloration [57, 62]. Therefore, the concept of "Self" in culturally diversified societies and the implications on cognition and emotions cannot be underestimated (for detailed review, see [63]). From applied perspective, intra-individual and contextual analyses, especially the former are vital because they provide more direct information on what competitive anxiety dimensions should be targeted during psychological intervention programmes [64]. Specifically, intra-individual differences in the intensity, interpretation (direction), and frequency as well as situational predictions of competitive anxiety in this study suggest that interventions designed to assist elite athletes from table tennis in managing their associated anxiety experiences should be idiosyncratic based (person-oriented) due to athletes' personal interpretation or appraisal of ever-changing situations characterized by competitive sport $[50,60,65]$. Sport psychologists and coaches could implement self-confidence management strategies including cognitive restructuring or mental rehearsals, thought stopping and other coping strategies that may minimize cognitive anxiety and possibly 
somatic arousals. These strategies may act as a buffering mechanism for elite athletes to avoid choking when situation demands $[10,66]$. Additionally, these psychological skills ought to be tested in natural field settings (ecological valid) to mimic real life experiences or situations than laboratory based testing, thus optimizing coping efficiency and effectiveness for elite athletes [67].

\section{Limitations}

This investigation was conducted on a relatively small and homogeneous sample of elite table tennis players competing in a major national competition. Hence, limits the generalizability of these findings to other groups of elite table tennis players, other sports, and participation levels. We believe that measured variables in this study were important, especially through the use of experience sampling method, warranted full examination. The momentary on-going individual assessment approach in the athletes' natural setting overcomes some of the weaknesses of retrospective designs that dominate the research literature by improving accuracy of self-reports $[67,68]$. Participants report how they would normally behave in retrospective designs compared to experience sampling method where participants are more likely to report how they actually feel in a particular situation [69]. This approach, likened to ecological momentary assessment, facilitates analysis of changes in stress, anxiety and coping appraisals in real time or close to real time occurrence $[44,51,70]$.

\section{Conclusions}

The results of this study involving Ghanaian athletes in table tennis indicate that the different dimensions of competitive anxiety are significantly predicted by different person related (age, gender) and situational (competitive experience) antecedents. Notably, studied variables influenced how Ghanaian elite table tennis athletes perceive associated anxiety symptoms and self-confidence. These variables may serve as reference points for the implementation of future psychological interventions aimed at improving these athletes' sport performance. The differentiation noted in the selected antecedents suggest that researchers could extend this investigation across different sports with different task characteristics, and at different levels of competition, and on other antecedents (e.g., perceived task difficulty) not captured in this study. These findings also give credence to the examination of competitive anxiety dimensions concurrently as against their separate assessments because they are triggered by different antecedents which may require anxiety dimension specific interventions.

\section{Acknowledgements}

The authors would sincerely thank University of Cape Coast, Ghana and Center of Excellence "Cognitive
Interaction Technology" CITEC, Bielefeld- Germany for the financial support and 2. A. Owusu-Ansah (Chief Coach, Ghana National Table Tennis Association), Raymond Donkor, and William Asare for their immense help during the data collection.

\section{References}

[1] Gould D, Jackson S, Finch L. Sources of stress in national champion figure skaters. Journal of Sport and Exercise Psychology. 1993; 15 (2): 134-159.

[2] Neil R, Wilson K, Mellalieu SD, Hanton S, Taylor J. Competitive anxiety intensity and interpretation: A two-study investigation into their relationship with performance. International Journal of Sport and Exercise Psychology. 2012; 10 (2): 96-111.

[3] Prapavessis H, Grove JR. Precompetitive emotions and shooting performance: The mental health and zone of optimal function models. The Sport Psychologist. 1991; 5 (3): 223-234.

[4] Fletcher D, Hanton S, Mellalieu SD. An organizational stress review: Conceptual and theoretical issues in competitive sport. Literature Reviews in Sport Psychology. 2006; 321-373.

[5] Hanton S, Connaughton D. Perceived control of anxiety and its relationship to self- confidence and performance. Research Quarterly for Exercise and Sport. 2002; 73 (1): 87-97.

[6] Martens R, Burton D, Vealey, RS, Bump LA, Smith DE. Development and validation of the Competitive State Anxiety Inventory-2 (CSAI-2). In R. Martens, R. S. Vealey, \& D. Burton (Eds.), Competitive anxiety in sport (pp. 117-213). Champaign, IL: Human Kinetics; 1990.

[7] Jones G, Swain ABJ. Predispositions to experience debilitative and facilitative anxiety in elite and non-elite performers. The Sport Psychologist. 1995; 9, 202-212.

[8] Swain ABJ, Jones G. Intensity and frequency dimensions of competitive state anxiety. Journal of Sport Sciences. 1993; 11, 533-542.

[9] Butt J, Weinberg R, Horn T. The intensity and directional interpretation of anxiety: Fluctuations throughout competition and relationship to performance. Sport Psychologist. 2003; 77 (1): $35-54$.

[10] Hanton S, Thomas O, Maynard I. Competitive anxiety responses in the week leading up to competition: The role of intensity, direction and frequency dimensions. Psychology of Sport and Exercise. 2004; 5, 169-181.

[11] Thomas O, Maynard I, Hanton S. Temporal aspects of competitive anxiety and self- confidence as a function of anxiety perceptions. The Sport Psychologist. 2004; 18, 172- 187.

[12] Hanton S, Cropley B, Neil R, Mellalieu SD, Miles A. Experience in sport and its relationship with competitive anxiety. International Journal of Sport and Exercise Psychology. 2007; 5 (1): 28-53.

[13] Hanton S, Neil R, Mellalieu SD, Fletcher D. Competitive experience and performance status: An investigation into multidimensional anxiety and coping. European Journal of Sport Science. 2008; 8 (3):143-152. 
[14] Mellalieu SD, Hanton S, O’Brien M. Intensity and direction dimensions of competitive anxiety as a function of sport type and experience. Scandinavian Journal of Science and Medicine in Sport. 2004; 14, 326-334.

[15] Jones G, Hanton S. Interpretation of anxiety symptoms and goal attainment expectations. Journal of Sport and Exercise Psychology. 1996; 18, 144-158.

[16] Jones JG, Swain A, Cale A. Antecedents of multidimensional competitive state anxiety and self-confidence in elite intercollegiate middle-distance runners. The Sport Psychologist. 1990; 4 (2):107-118.

[17] Cooley EJ. Situational and trait determinants of competitive state anxiety. Perceptual and motor skills. 1987; 64 (3): 767773.

[18] Gruber JJ, Beachamp D. Relevancy of the competitive state anxiety inventory in a sport environment. Research Quarterly. $1979 ; 50,207-214$

[19] Hardy L, Jones G. Current issues and future directions for performance-related research in sport psychology. Journal of Sports Sciences. 1994; 12 (1): 61-92.

[20] Hanton S, Jones G. Antecedents of intensity and direction dimensions of competitive anxiety as a function of skill. Psychological Reports. 1997; 81, 1139-1147.

[21] Lane A, Terry P, Karageorghis C. Antecedents of multidimensional competitive state anxiety and selfconfidence in duathletes. Perceptual and Motor Skills. 1995; 80 (3): 911- 919.

[22] Thomas O, Hanton S, Maynard I. Anxiety responses and psychological skill use during the time leading up to competition: Theory to practice I. Journal of Applied Sport Psychology. 2007; 19 (4):379-97.

[23] Eubank M, Collins D. Coping with pre-and in-event fluctuations in competitive state anxiety: A longitudinal approach. Journal of Sports Sciences. 2000; 18 (2):121-131.

[24] Fernandes MG, Nunes SAN, Vasconcelos-Raposo J, Fernandes HM. Factors influencing competitive anxiety in Brazilian athletes. Revista Brasileira de Cineantropometria \& Desempenho Humano. 2013; 15 (6):705-714.

[25] Krane V, Williams JM. Cognitive anxiety, somatic anxiety, and confidence in track and field athletes: The impact of gender, competitive level and task characteristics. International Journal of Sport Psychology. 1994; 25, 203-217.

[26] Russell WD, Robb M, Cox RH. Sex, sport, situation, and competitive state anxiety. Perceptual and Motor Skills. 1998; $86(3): 816-818$.

[27] Hagan Jnr. JE, Pollmann D, Schack T. Interaction between gender and skill on competitive state anxiety using the timeto-event paradigm: What roles do intensity, direction and frequency dimensions play? Frontiers in Psychology. 2017; 8, 692.

[28] Woodman T, Hardy L. The relative impact of cognitive anxiety and self-confidence upon sport performance. A metaanalysis. Journal of Sports Sciences. 2003; 21, 443-457.

[29] Hanton S, Mellalieu SD, Hall R. Self-confidence and anxiety interpretation: A qualitative investigation. Psychology of Sport and Exercise. 2004; 5 (4): 477-495.
[30] Mellalieu SD, Neil R, Hanton S. An investigation of the mediating effects of self- confidence between anxiety intensity and direction. Research Quarterly for Sport and Exercise. 2006; 77, 263-270.

[31] Perry JD, Williams JM. Relationship of intensity and direction of competitive trait anxiety to skill level and gender in tennis. The Sport Psychologist. 1998; 12, 169-179.

[32] Cerin E, Szabo A, Hunt N, Williams C. Temporal patterning of competitive emotions: A critical review. Journal of Sport Sciences. 2000; 18: 605-625.

[33] Hammermeister J, Burton D. Anxiety and the Ironman: Investigating the antecedents and consequences of endurance athletes' state anxiety. The Sport Psychologist. 1995; 9 (1): 29- 40.

[34] Modroño C, Guillen F. Anxiety characteristics of competitive windsurfers: relationships with age, gender, and performance outcomes. Journal of Sport Behavior. 2011; 34 (3): 281.

[35] Sanchez-Garcia N, Villaverde-Gutiérrez C, Ramírez-Rodrigo J, Ruiz-Villaverde G, Arroyo-Morales M, Ruíz-Villaverde R. $\mathrm{ACTH}$, beta-endorphin, and leves of anxiety in middle-age athletes. International Journal of Sport Psychology. 2004; 35 (2):149-156.

[36] Mann DT, Williams AM, Ward P, Janelle CM. Perceptualcognitive expertise in sport: A meta-analysis. Journal of Sport and Exercise Psychology. 2007; 29 (4):457.

[37] Raab M, Masters RS, Maxwell JP. Improving the 'how'and 'what'decisions of elite table tennis players. Human Movement Science. 2005; 24 (3):326-344.

[38] Hanton S, Mellalieu SD, Young SG. A qualitative investigation of the temporal patterning of the precompetitive anxiety response. Journal of Sports Sciences. 2002; 20 (11):911-928.

[39] Hanton S, Wadey R, Connaughton D. Debilitative interpretations of competitive anxiety: A qualitative examination of elite performers. European Journal of Sport Science. 2005; 5 (3):123-36.

[40] Jones G, Swain ABJ. Intensity and direction dimensions of competitive state anxiety and relationships with competitiveness. Perceptual and Motor Skills. 1992; 74, 467472 .

[41] Hanton S, Jones G, Mullen R. Intensity and direction of competitive state anxiety as interpreted by rugby players and rifle shooters. Perceptual and Motor Skills. 2000; 90, 513-521.

[42] Swain A, Jones G. Explaining performance variance: The relative contribution of intensity and direction dimensions of competitive state anxiety. Anxiety, Stress, and Coping. 1996; 9 (1): 1-18.

[43] Wiggin MS. Anxiety intensity and direction: Preperformance temporal patterns and expectations in athletes. Journal of Applied Sport Psychology. 1998; 10, 201-211.

[44] Lazarus RS. Stress and emotion: a new synthesis. New York: Springer. 1999.

[45] Uphill MA, Jones MV. Antecedents of emotions in elite athletes: A cognitive motivational relational theory perspective. Research Quarterly for Exercise and Sport. 2007; 78 (2): 79- 89 . 
[46] Tabachnick BG, Fidell LS. Using multivariate statistics (5th ed.). Boston, MA: Allyn \& Bacon. 2007.

[47] Field A. Discovering statistics using SPSS. Sage publications. 2009.

[48] Jones J, Hardy LE. Stress and performance in sport. John Wiley \& Sons. 1990.

[49] Pensgaard AM, Ursin H. Stress, control, and coping in elite athletes. Scandinavian Journal of Medicine \& Science in Sports. 1998; 8 (3):183-189.

[50] Hanin YL. Coping with anxiety in sport. Coping in sport: Theory, methods and related constructs. 2010:159-75.

[51] Lazarus RS, Folkman S. Coping and adaptation. The handbook of behavioral medicine. 1984; 282-325.

[52] Hardy L. A catastrophe model of performance in sport.. In J. Graham \& L. Hardy (Eds.), Stress and performance in sport (pp. 81-106). New York: Wiley. 1990.

[53] Jones G, Hanton S, Swain, ABJ. Intensity and interpretation of anxiety symptoms in elite and non-elite sports performers. Personality and Individual Differences. 1994; 17, 657-663.

[54] Carver CS, Scheier MF. Functional and dysfunctional responses to anxiety: The interaction between expectancies and self-focused attention. Self-related cognitions in anxiety and motivation. 1986; 111-141.

[55] Carver CS, Scheier MF. A control-process perspective on anxiety. Anxiety Research. 1988; 1 (1):17-22.

[56] Jones G. More than just a game: Research developments and issues in competitive anxiety in sport. British Journal of Psychology. 1995; 86, 449-478.

[57] Nicholls AR, Polman RC. Coping in sport: A systematic review. Journal of Sports Sciences. 2007; 25 (1):11-31.

[58] Hanton S, Cropley B, Neil R, Mellalieu SD, Miles A. Experience in sport and its relationship with competitive anxiety. International Journal of Sport and Exercise Psychology. 2007; 5 (1): 28-53.

[59] Nideffer RN. Use of the Test of Attentional and Interpersonal Style (TAIS) in sport. The Sport Psychologist. 1990; 4 (3): 285-300.
[60] Nideffer RN. Attentional control training. In R. N. Singer, M. Murphey, \& L. K. Tennant (Eds). Handbook of research on sport psychology. Handbook of research on sport psychology. New York: Macmillan. 1993.

[61] Carver CS, Scheier MF. Stress, coping, and self-regulatory processes. In L. A. Pervin, \& O. P. John (Eds.), Handbook of personality: Theory and research (2nd ed.) (pp. 553-575). New York: Guilford Press. 1999.

[62] Dzokoto V. Different ways of feeling: emotion and somatic awareness in Ghanaians and Euro-Americans. Journal of Social, Evolutionary, and Cultural Psychology. 2010; 4 (2):68.

[63] Markus HR, Kitayama S. Culture and the self: Implications for cognition, emotion and motivation. Psychological Review. 1991; 98 (2): 224.

[64] Cerin E. Anxiety versus fundamental emotions as predictors of perceived functionality of pre-competitive emotional states, threat, and challenge in individual sports. Journal of Applied Sport Psychology. 2003; 15, 223-238.

[65] Hanin YL. Emotions in sport. Champaign, IL: Human Kinetics. 1999.

[66] Ryska TA. Cognitive-behavioral strategies and precompetitive anxiety among recreational athletes. The Psychological Record. 1998; 48 (4): 697.

[67] Nicholls AR, Holt NL, Polman RCJ. A phenomenological analysis of coping effectiveness in golf. The Sport Psychologist. 2005a; 19, 111-130.

[68] Brandstätter H. Emotional responses to other persons in everyday life situations. Journal of Personality and Social Psychology. 1983; 45 (4): 871.

[69] Smith RE, Leffingwell TR, Ptacek JT. Can people remember how they coped? Factors associated with discordance between same-day and retrospective reports. Journal of Personality and Social Psychology. 1999; 76 (6):1050.

[70] Conner TS, Tennen H, Fleeson W, Barrett LF. Experience sampling methods: A modern idiographic approach to personality research. Social and Personality Psychology Compass. 2009; 3 (3): 292-313. 